\title{
Exploring the combination and modular characteristics of herbs for alopecia treatment in traditional Chinese medicine: an association rule mining and network analysis study
}

Jungtae Leem ${ }^{1,2+}$, Wonmo Jung ${ }^{3,4 \dagger}$, Yohwan Kim5 ${ }^{5}$ Bonghyun Kim ${ }^{6,8}$ and Kyuseok Kim ${ }^{7,8^{*}}$ (i)

\begin{abstract}
Background: Although alopecia affects the quality of life, its pathogenesis is unknown, because cellular interactions in the hair follicle are complex. Several authors have suggested using herbal medicine to treat alopecia, and bioinformatics and network pharmacology may constitute a new research strategy in this regard because herbal medicines contain various chemical components. This study used association rule mining (ARM) and network analysis to analyze the combinations of medicinal herbs used to treat alopecia.

Methods: We searched Chinese, Korean, and English databases for literature about alopecia treatment, extracting the names of each herbal prescription and herb. The meridian tropism and classification category of each herb were also investigated. Using ARM, we identified frequently combined two-herb and three-herb sets. Using network analysis, we divided the herbs into several modules according to prescription pattern.

Results: Fifty-six articles and 489 herbal medicines were included - 312 internal and 177 external medicines. Among the 312 medicinal herbs used in internal medicine group, the most frequently combined two-herb set was Polygonum multiflorum Thunb. (何首烏) and Angelica sinensis (Oliv.) Dlels (當歸). The most frequently used three-herb combination was Polygonum multiflorum Thunb., Angelica sinensis (Oliv.) Dlels, and Ligusticum chuanxiong Hort. (川芎). In network analysis, three modules were identified. The herbs of Module 1 were related to the liver and kidney meridians, and those of Module 3 were related to the Stomach meridian.

Conclusions: We identified the frequency, characteristics, and functional modules of herb combinations frequently used in alopecia treatment. We confirmed the value of classical medicinal herb theory. This finding will prompt further bioinformatics and network pharmacology research on alopecia.
\end{abstract}

Keywords: Medicinal herb, Alopecia, Association rule mining, Network analysis, Bioinformatics

\footnotetext{
* Correspondence: kmdkskim@khu.ac.kr

†Jungtae Leem and Wonmo Jung contributed equally to this work.

${ }^{7}$ Department of Ophthalmology, Otolaryngology \& Dermatology, College of Korean Medicine, Kyung Hee University, 26 Kyungheedae-ro,

Dongdaemun-gu, Seoul 02447, Republic of Korea

${ }^{8}$ Department of Ophthalmology, Otolaryngology \& Dermatology, Kyung Hee

University Korean Medicine Hospital, 23 Kyungheedae-ro, Dongdaemun-gu,

Seoul 02447, Republic of Korea

Full list of author information is available at the end of the article
}

(c) The Author(s). 2018 Open Access This article is distributed under the terms of the Creative Commons Attribution 4.0 International License (http://creativecommons.org/licenses/by/4.0/), which permits unrestricted use, distribution, and reproduction in any medium, provided you give appropriate credit to the original author(s) and the source, provide a link to the Creative Commons license, and indicate if changes were made. The Creative Commons Public Domain Dedication waiver (http://creativecommons.org/publicdomain/zero/1.0/) applies to the data made available in this article, unless otherwise stated. 


\section{Background}

Hair loss affects up to $50 \%$ of both men and women throughout their lives, causing anxiety and disability that can have a significant effect on the patient's quality of life. [1, 2] The condition has been linked to an autoimmune disorder of the hair follicle, genetic background, hormones, medication, and psychological stress, which can alter the hair follicle cycle $[3,4]$ Many studies have attempted to elucidate the pathogenesis of hair loss. However, the complex molecular interactions between the cells of the hair follicle have not been fully understood, and the exact cause of alopecia is still unknown.

Finasteride and minoxidil have been approved by the Food and Drug Administration of the United States (FDA, USA) to promote hair growth. However, the effectiveness of these drugs varies greatly among individuals, and they have unwanted side effects. Relatedly, many alopecia patients are concerned about the side effects associated with conventional therapies, and complementary and alternative medicine (CAM) has thus been suggested as a new treatment for alopecia. [5] In particular, traditional Chinese medicine (TCM) is an important part of healthcare in East Asia, and it is commonly used to treat alopecia patients. [5, 6]

Herbal medicine prescriptions consist of various herbal preparations. Thus, using the scientific method, researchers must investigate frequently used herbal combinations and categorize them. However, in the TCM literature, few narrative reviews have focused on herbs for alopecia treatment, [6, 7] and the Chinese, Korean, and European research databases contain no studies that have classified herbs for alopecia treatment using statistical methods such as data mining.

Previous studies based on TCM pattern identification have shown that deficiency of liver and kidney (肝腎不 足), deficiency of $q i$ and blood (氣血兩虛), $q i$ stagnation and blood stasis (氣滯血瘀), and blood-heat (血熱) are the main patterns linked to alopecia. [6, 7] However, because a diverse range of herbal ingredients are used in TCM and because interactions between herbal medicine and the human body are complex, the mechanism underlying these TCM patterns is still unknown. [8] Recently, statistical methods such as data mining have been applied to TCM research. However, to the best of our knowledge, no studies have used network analysis methods to assess herbal medicine used in hair loss treatment.

Therefore, this study aimed to identify-using association rule mining (ARM) - which herbal combinations are used frequently in hair loss treatment and to analyze the modular characteristics of these treatments using network analysis.

\section{Methods}

\section{Criteria for study inclusion}

We included all kinds of studies regardless of the study design, and we did not restrict the type of alopecia or herbal medicine used. Thus, all kinds of herbal medicines were considered-extracts, decoctions, pills, and even external application. There were no restrictions on sex, age, disease duration, or disease severity. The outcome of clinical studies was not considered.

\section{Search methods}

We conducted an electronic search of the Chinese, English, and Korean databases from their inception to March 2017. We searched one Chinese database: the China National Knowledge Infrastructure (CNKI) database, three English databases: Embase, Medline (via PubMed), and the Central Register of Controlled Trials (CENTRAL), and one Korean database: the Oriental Medicine Advanced Searching Integrated System (OASIS), which specializes in traditional Korean Medicine research articles. [9] The following search terms for alopecia were included: "Alopecia", "Alopecia areata", "Diffuse alopecia", "Androgenic alopecia," and "Female pattern hair loss." An additional file describes details of the search terms and search strategies used in each database to identify alopecia (see Additional file 1).

\section{Data extraction}

We extracted the name of each herbal formula, the medicinal herbs that comprised it, its origin (name of article or ancient literature), author, publication year, and internal/external application. The names of the herbs followed the Chinese Pharmacopoeia 2015 edition, $[8,10]$ which can be found on the OASIS and KIOM Herbarium website (http://boncho.kiom.re.kr/herbarium/codex.php). [11] The categorization of each herb followed Phytology [12] and Chinese Pharmacy. [13] The names of the 20 classification categories of medicinal herbs are as follows: (1) Exterior-releasing medicinal (解 表藥), (2) Heat-clearing medicinal (淸熱藥), (3) Purgative medicinal (瀉下藥), (4) Wind-dampness dispelling medicinal (祛風濕藥), (5) dampness-resolving medicinal (化濕藥), (6) Dampness-draining diuretic medicinal (利 水滲濕藥), (7) Interior-warming medicinal (溫裏藥), (8) Qi-regulating medicinal (理氣藥), (9) Digestant medicinal (消食藥), (10) worm-expelling medicinal (驅 蟲藥), (11) hemostatic (medicinal) (止血藥), (12) Blood-activating and stasis-dispelling medicinal (活血祛 瘀藥), (13) Cough-suppressing and panting-calming medicinal (止咳平喘藥), (14) Tranquillizing medicinal (安 神藥), (15) Liver-pacifying medicinal (平肝藥), (16) Orifice-opening medicinal (開㝑藥), (17) Tonifying and replenishing medicinal (補益藥), (18) Astringent medicinal (收涉藥), (19) Emetic medicinal (湧吐藥), and (20) External application medicinal (外用藥). 


\section{Data analysis}

First, we compared the meridian tropism and classification category of each medicinal herb between the internal and external applications. The criteria for meridian tropism followed the classification of the Phytology [12] and Chinese Pharmacy. [13] Next, we conducted a data mining analysis using ARM and network analysis. Because the mechanism of action differs depending on the route of administration, we only carried out this analysis on the internal application formulas only, not the external application formulas. Using ARM, we identified the most frequently used two-herb combination and three-herb combination. Using network analysis, we categorized the herbs used in alopecia treatment into several modules.

\section{Association rule mining}

Using the list of prescriptions used to treat hair loss, we searched for combinations of herbs repeatedly used over several prescriptions. For this purpose, we applied ARM, which uncovers interesting relationships in large datasets, to our data. [14] Because ARM is generally used in business to analyze customers' purchase data, the terms "item" and "transaction" are widely used. In our analysis, the herbs were defined as items, and the prescriptions were defined as transactions recording co-occurrences of items. We let $H=\{h 1, h 2, \ldots h d\}$ be the set of all herbs in the bald prescription data, and $\mathrm{P}=\{\mathrm{p} 1, \mathrm{p} 2, \ldots, \mathrm{pn}\}$ be the set of all prescriptions. In ARM, a collection of zero or more items is termed an itemset. An association rule is an expression of the form $\mathrm{X} \rightarrow \mathrm{Y}$, where $\mathrm{X}$ and $\mathrm{Y}$ are disjoint itemsets. The expression represents the relationship between the occurrences of itemset $\mathrm{X}$ and itemset $Y$. The strength of the association rule can be measured in terms of its support, confidence, and lift. Support determines how often a rule is applicable to a given data set, while confidence determines how frequently items in $\mathrm{Y}$ appear in transactions that contain $\mathrm{X}$. Support indicates how frequently the rule can be applied to a given set of data, and confidence indicates how often $\mathrm{Y}$ appears in transactions containing $\mathrm{X}$. Lift is the ratio of observed support to expected support when $\mathrm{X}$ and $\mathrm{Y}$ are independent. Support is a measure of whether an association between $\mathrm{X}$ and $\mathrm{Y}$ happens by chance, and confidence represents the reliability of the association. Lift values larger than 1 indicate that the occurrences the two itemsets are dependent on each other. These measures suggest a strong co-occurrence relationship between itemsets $\mathrm{X}$ and $\mathrm{Y}$. In the present study, ARM for combinations of two herbs and three herbs was applied using the a priori package of $\mathrm{R}$ ( $\mathrm{R}$ Core Team (2013). R: A language and environment for statistical computing. R Foundation for Statistical Computing, Vienna, Austria), and minimum thresholds on support and confidence were set at 0 and 1 , respectively.

\section{Network analysis}

ARM cannot inspect the overall pattern of how herbs are used together, because it assesses the association between limited numbers of itemsets. Therefore, we constructed a network that connected the herbs used together in alopecia prescriptions. We also examined the modularity analysis to identify patterns and group herbs into specific modules. The network between the herbs was configured using Python's networkx ${ }^{\ominus}$ package (https://networkx.github.io/). [15] The nodes of the network were defined as all the herbs that appeared in alopecia prescriptions. The herbs that appeared together in at least one prescription were defined as having a linkage between each other, and the network was constructed as a graph that weighted connections based on the number of co-occurrences in different prescriptions. The dose of the herb in each prescription was not considered in determining weight or linkage. Modularity analysis and network visualization were performed using Gephi. [16] Modularity analysis was performed using the Louvaine method, with a resolution value of 1.0 [17]. Visualization was performed using a circular layout in which modules were classified into categories.

To observe differences among the modules identified modularity analysis, the meridian tropism of the herbs composing each module was examined. Meridian tropism is the notion that a herb predominantly exerts a therapeutic effect on a specific organ or meridian in the human body [18]. The meridian tropism (引經) of each herb is recorded in the classic book, and it reveals the characteristics of each herb from the perspective of Korean medicine. Based on the meridian tropism of each herb listed in herbal textbooks and the Korean Intellectual Property Office database, we investigated the ratios of therapeutic preferences for each meridian of the herbs in each module. The permutation test was then applied to find statistically significant meridian preferences. Briefly, a list of module labels of herbs was randomly permutated, the meridian preference ratio per module was calculated, and the process was repeated 10,000 times to obtain a null distribution of meridian preference ratios. A $p$-value was then calculated based on the location of the observations within the simulated null distribution. We tested 12 meridian preferences separately for each module, with a correction for multiple testing using the false discovery rate.

\section{Results}

\section{Study selection}

A total of 585 articles were screened: 286 in the English databases, 73 in CNKI, and 226 in OASIS. Ultimately, 56 articles were included after screening of the full text: 12 from the English databases, [19-30], 13 from CNKI, [6, 31-42] and 31 from OASIS. [43-73] Details of the 
screening process are shown in the PRISMA flow chart (Fig. 1).

\section{Herbal medicine and medicinal herbs}

From the 56 articles, 489 herbal medicines (312 internal and 177 external) and 374 medicinal herbs were identified. Among the 312 internal medicines, 258 medicinal herbs were identified. Among the 177 external medicines, 257 medicinal herbs were identified. Many medicinal herbs were used in both internal medicine and external applications. Table 1 lists the frequently described medicinal herbs.

\section{Association rule mining results for two-herb and three- herb combinations}

The frequency trend of the 258 herbs in the 312 internal alopecia prescriptions were analyzed using the a priori ARM method to elucidate whether certain herbs are used more frequently in combinations of two or three. The top 10 association rules between two herbs are described in Table 2. The association of Polygonum multiflorum Thunb. (何首烏) and Angelica sinensis (Oliv.) Dlels (當歸) had the highest support, with 38.5\%. The six possible pairs from a group of 4 herbs-Polygonum multiflorum Thunb. (何首烏), Angelica sinensis (Oliv.) Dlels (當歸), Ligusticum chuanxiong Hort. (川芎), and Rehmannia glutinosa Libosch. (Prepared) (熟地黄)— were listed as the top 6 association rules, indicating that these four herbs are the most commonly prescribed herbs, and that they are frequently used together. Other rules in the top 10 list contained Ligustrum lucidum Ait. (女貞子), Lycium barbarum L. (枸杞子), and Eclipta prostrata L. (旱蓮草) as additional combination herbs.

The top 10 association rules for three-herb combinations are described in Table 3. The result again showed the importance of four main herbs. Of the four possible combinations of three herbs from among the four main herbs-Polygonum multiflorum Thunb. (何首烏), Angelica sinensis (Oliv.) Dlels (當歸), Ligusticum chuanxiong Hort. (川芎), and Rehmannia glutinosa Libosch. (Prepared) (熟 地黃) - three combinations were listed in the top 4 association rules, with support of $23.4,21.5$, and $21.2 \%$, respectively. One other three-herb combination of the four main herbs, excluding Angelica sinensis (Oliv.) Dlels (當歸), was listed as the No. 8 association rule.

Paeonia lactiflora Pall. (白药藥) did not appear in the top 10 association rules of two-herb combinations, but it was listed as a member of three-herb combinations in

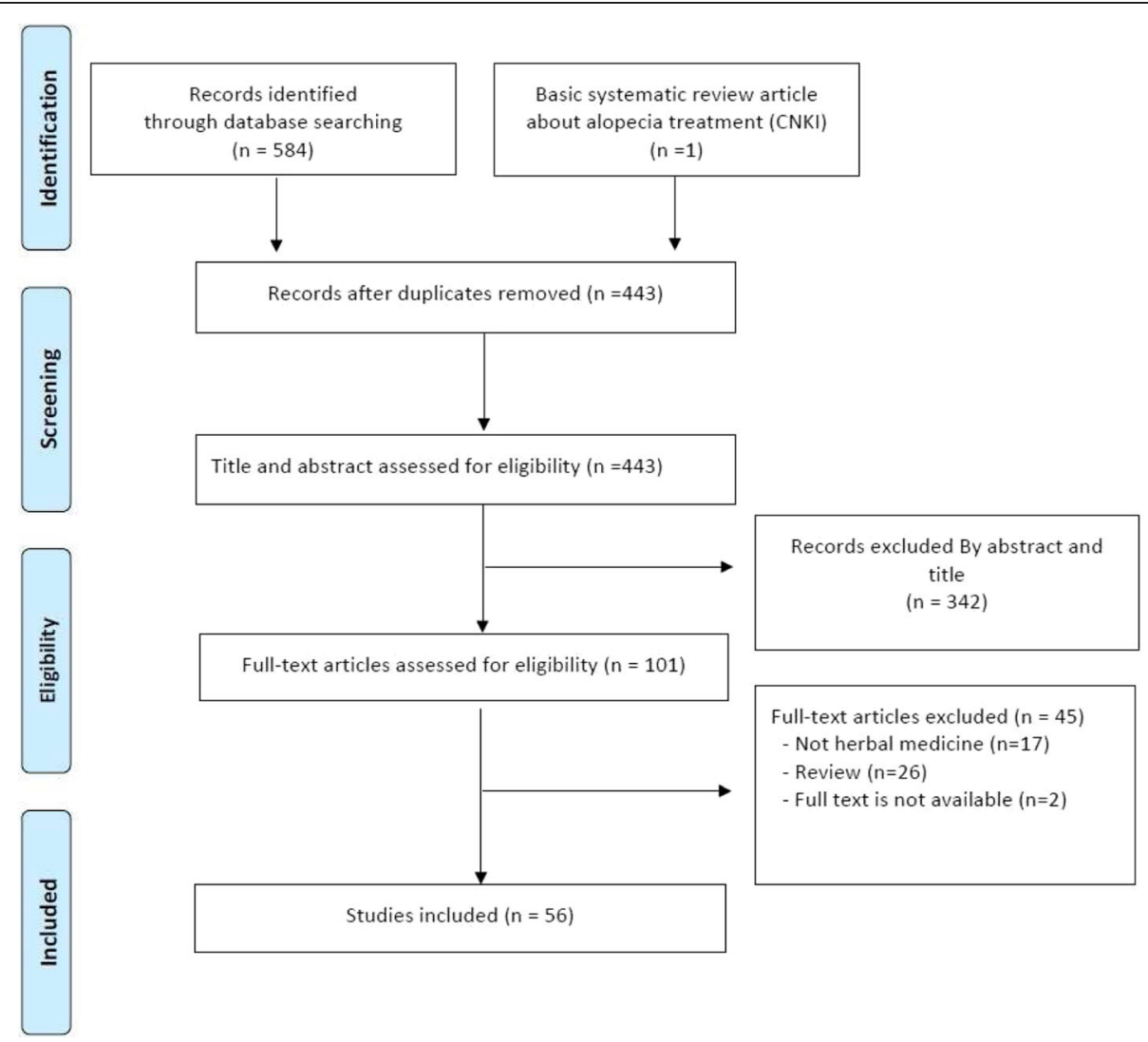

Fig. 1 PRISMA flow diagram 
Table 1 Frequency, module, and meridian tropism of the top 10 internal and external medicinal herbs

\begin{tabular}{|c|c|c|c|c|c|c|c|c|c|c|c|c|c|c|c|c|}
\hline $\begin{array}{l}\text { Internal/ } \\
\text { External }\end{array}$ & Medicinal Herb & Category & Frequency & Module & $\begin{array}{l}\mathrm{LR} \\
\text { (肝) }\end{array}$ & $\begin{array}{l}\text { HT } \\
\text { (心) }\end{array}$ & $\begin{array}{l}P C \\
\text { (心包) }\end{array}$ & $\begin{array}{l}\mathrm{SP} \\
\text { (脾) }\end{array}$ & $\begin{array}{l}\text { LU } \\
\text { (肺) }\end{array}$ & $\begin{array}{l}\mathrm{Kl} \\
\text { (腎) }\end{array}$ & $\begin{array}{l}\text { GB } \\
\text { (膽) }\end{array}$ & $\begin{array}{l}\mathrm{SI} \\
\text { (小腸) }\end{array}$ & $\begin{array}{l}\text { TE } \\
\text { (三焦) }\end{array}$ & $\begin{array}{l}\text { ST } \\
\text { (胃) }\end{array}$ & $\begin{array}{l}\text { LI } \\
\text { (大腸) }\end{array}$ & $\begin{array}{l}\mathrm{BL} \\
\text { (膀胱) }\end{array}$ \\
\hline$\overline{I \& E}$ & $\begin{array}{l}\text { Angelica sinensis (Oliv.) } \\
\text { Dlels (當歸) }\end{array}$ & 17 & $\begin{array}{l}171(I) \\
27(E)\end{array}$ & 1 & $\bar{Y}$ & $Y$ & & $\bar{Y}$ & & & & & & & & \\
\hline I\&E & $\begin{array}{l}\text { Ligusticum chuanxiong } \\
\text { Hort. (川芦) }\end{array}$ & 12 & $\begin{array}{l}132(I) \\
32(E)\end{array}$ & 1 & Y & & Y & & & & Y & & & & & \\
\hline । & $\begin{array}{l}\text { Polygonum multiflorum } \\
\text { Thunb. (何首烏) }\end{array}$ & 17 & 175 & 1 & Y & & & & & Y & & & & & & \\
\hline । & $\begin{array}{l}\text { Rehmannia glutinosa } \\
\text { Libosch. (Prepared) } \\
\text { (熟地黄) }\end{array}$ & 17 & 137 & 1 & Y & & & & & Y & & & & & & \\
\hline । & $\begin{array}{l}\text { Poria cocos (Schw.) } \\
\text { Wolf (茯苓) }\end{array}$ & 6 & 103 & 3 & & Y & & Y & & Y & & & & & & \\
\hline । & $\begin{array}{l}\text { Ligustrum lucidum Ait. } \\
\text { (女貞子) }\end{array}$ & 17 & 96 & 1 & Y & & & & & Y & & & & & & \\
\hline । & $\begin{array}{l}\text { Rehmannia glutinosa } \\
\text { Libosch. (生地黄) }\end{array}$ & 2 & 95 & 1 & Y & Y & & & & Y & & & & & & \\
\hline । & $\begin{array}{l}\text { Glycyrrhiza uralensis } \\
\text { Fisch. (甘草) }\end{array}$ & 8 & 90 & 3 & & & & & & & & & & & & \\
\hline । & $\begin{array}{l}\text { Eclipta prostrata L. } \\
\text { (旱蓮草) }\end{array}$ & 17 & 89 & 1 & Y & & & & & Y & & & & & & \\
\hline । & $\begin{array}{l}\text { Lycium barbarum L. } \\
\text { (枸杞子) }\end{array}$ & 17 & 88 & 1 & Y & & & & Y & Y & & & & & & \\
\hline E & $\begin{array}{l}\text { Platycladus orientalis } \\
\text { (L.) Franco (側柏葉) }\end{array}$ & 11 & 51 & 1 & Y & & & & Y & & & & & & Y & \\
\hline E & $\begin{array}{l}\text { Angelica dahurica } \\
\text { (Fisch. ex Hoffm.) } \\
\text { Benth. et Hook.f. (白芷) }\end{array}$ & 1 & 40 & 2 & & & & & Y & & & & & Y & Y & \\
\hline E & $\begin{array}{l}\text { Vitex trifolia L. var. } \\
\text { simplicifolia Cham. } \\
\text { (蔓荊子) }\end{array}$ & 1 & 34 & 2 & Y & & & & & & & & & Y & & Y \\
\hline E & $\begin{array}{l}\text { Aconitum carmichaelii } \\
\text { Debx. (附子) }\end{array}$ & 7 & 29 & 2 & & Y & & Y & & Y & & & & & & \\
\hline E & $\begin{array}{l}\text { Zanthoxylum schinifolium } \\
\text { Sieb. et Zucc. (蜀椒) }\end{array}$ & 7 & 26 & 2 & & & & Y & Y & Y & & & & Y & & \\
\hline E & $\begin{array}{l}\text { Carthamus tinctorius L. } \\
\text { (紅花) }\end{array}$ & 12 & 25 & 1 & Y & Y & & & & & & & & & & \\
\hline E & $\begin{array}{l}\text { Salvia miltiorrhiza Bge. } \\
\text { (丹氽) }\end{array}$ & 12 & 25 & 1 & Y & Y & Y & & & & & & & & & \\
\hline E & $\begin{array}{l}\text { Saposhnikovia divaricata } \\
\text { (Turcz.) Schischk. (防風) }\end{array}$ & 1 & 23 & 2 & Y & & & Y & & & & & & & & Y \\
\hline
\end{tabular}

BL Bladder meridian, GB Gall bladder meridian, HT Heart meridian, $K I$ Kidney meridian, $L$ Large intestine meridian, $L R$ Liver meridian, $L U$ Lung meridian, $P C$ Pericardium meridian, SI Small intestine meridian, SP Spleen meridian, ST Stomach meridian, TE Triple energizer meridian

Angelica sinensis (Oliv.) Dlels (當歸) was the 2nd most commonly used medicinal herb in the internal medicines category and the 6th most commonly used in the external application category

Ligusticum chuanxiong Hort. (川芎) was the 4th most commonly used medicinal herb in the internal medicines category and the 4th most commonly used in the external application category

E, External application, I Internal Medicine, I\&E Commonly used in external application and internal medicine

Category of each medicinal herb: 1, Exterior-releasing medicinal (解表藥); 2, Heat-clearing medicinal (清熱藥); 4, Wind-dampness dispelling medicinal (祛風濕藥);

5, Dampness-resolving medicinal (化濕藥); 6, Dampness-draining diuretic medicinal (利水滲濕藥); 7, Interior-warming medicinal (溫裏藥); 8, Qi-regulating medicinal (理氣藥); 9, Digestant medicinal (消食藥); 11, Hemostatic medicinal (止血藥); 12, Blood-activating and stasis-dispelling medicinal (活血祛瘀藥); 13, Cough-suppressing and panting-calming medicinal (止咳平喘藥); 14, Tranquillizing medicinal (安神藥); 15, Liver-pacifying medicinal (平肝藥); 17, Tonifying and replenishing medicinal (補益藥); 18, Astringent medicinal (收涉藥)

association rule Nos. 5 and 9. Cuscuta chinensis Lam. (菟絲子) was also not shown in the top 10 association rules of two-herb combinations, but it did appear among the top 10 association rules of three-herbs combinations.

\section{Modularity analysis of herb networks and characteristic of modules}

Based on the frequency of co-occurrences of herb pairs, we constructed a weighted unidirectional network, assigning "frequency of co-occurrence" as a weight value 
Table 2 Association rule mining results (Length of herb set = 2)

\begin{tabular}{|c|c|c|c|c|}
\hline Associated Herbs & support & confidence & lift & frequency \\
\hline Polygonum multiflorum Thunb. (何首烏), Angelica sinensis (Oliv.) Dlels (當歸) & 0.385 & 0.702 & 1.251 & 120 \\
\hline Ligusticum chuanxiong Hort. (川芎), Angelica sinensis (Oliv.) Dlels (當歸) & 0.343 & 0.811 & 1.479 & 107 \\
\hline Rehmannia glutinosa Libosch. (Prepared) (熟地黄), Angelica sinensis (Oliv.) Dlels (當歸) & 0.304 & 0.693 & 1.265 & 95 \\
\hline Rehmannia glutinosa Libosch. (Prepared) (熟地黄), Polygonum multiflorum Thunb. (何首烏) & 0.279 & 0.635 & 1.132 & 87 \\
\hline Ligusticum chuanxiong Hort. (川芎), Polygonum multiflorum Thunb. (何首烏) & 0.263 & 0.621 & 1.108 & 82 \\
\hline Ligusticum chuanxiong Hort. (川芎), Rehmannia glutinosa Libosch. (Prepared) (熟地黄) & 0.253 & 0.598 & 1.363 & 79 \\
\hline Ligustrum lucidum Ait. (女貞子), Polygonum multiflorum Thunb. (何首烏) & 0.231 & 0.750 & 1.337 & 72 \\
\hline Lycium barbarum L. (枸杞子), Polygonum multiflorum Thunb. (何首鳥) & 0.221 & 0.784 & 1.398 & 69 \\
\hline Ligustrum lucidum Ait. (女貞子), Eclipta prostrata L. (旱蓮草) & 0.221 & 0.719 & 2.520 & 69 \\
\hline Eclipta prostrata L. (早蓮草), Polygonum multiflorum Thunb. (何首烏) & 0.215 & 0.753 & 1.342 & 67 \\
\hline
\end{tabular}

of the connection. We then performed a modularity analysis on the weighted graph using the Louvain method. The results showed that the network could be divided into three modules, with a modularity value of 0.141 . The number of herbs comprising each module were 58, 86 , and 111, respectively (Fig. 2). Unconnected single herbs were excluded from the modularity analysis. The top 20 most frequent herbs in each module are described in Table 4.

The frequency trend for meridian tropism in each module is described in Fig. 3. Significantly high and low meridian tropism frequency ratios were found in each module using the permutation test. Module 1 had significantly more herbs that preferred "Liver," while Module 3 had significantly more herbs that preferred "Stomach."

\section{Discussion}

We systematically searched literature for alopecia treatment formulas. The following herbs were frequently used in internal medicine: Polygonum multiflorum Thunb., Angelica sinensis (Oliv.) Dlels, Rehmannia glutinosa Libosch. (Prepared), and Ligusticum chuanxiong Hort. Conversely, Platycladus orientalis (L.) Franco, Angelica dahurica (Fisch. ex Hoffm.) Benth. et Hook.f., Vitex trifolia L. var. simplicifolia Cham., and Ligusticum chuanxiong Hort. were frequently used in external applications. Internal medicine and external application differed in terms of pharmacological efficacy and meridian tropism. Using the ARM method, the most frequently used two-herb combinations were (1) Polygonum multiflorum Thunb. and Angelica sinensis (Oliv.) Dlels, and (2) Ligusticum chuanxiong Hort. and Rehmannia glutinosa Libosch.

Table 3 Association rule mining results (Length of herb set =3)

\begin{tabular}{|c|c|c|c|c|}
\hline Associated Herbs & support & confidence & lift & frequency \\
\hline $\begin{array}{l}\text { Ligusticum chuanxiong Hort. (川芦), Polygonum multiflorum Thunb. (何首烏), Angelica sinensis } \\
\text { (Oliv.) Dlels (當歸) }\end{array}$ & 0.234 & 0.890 & 1.624 & 73 \\
\hline $\begin{array}{l}\text { Rehmannia glutinosa Libosch. (Prepared) (熟地黄), Polygonum multiflorum Thunb. (何首鳥), } \\
\text { Angelica sinensis (Oliv.) Dlels (當歸) }\end{array}$ & 0.215 & 0.770 & 1.405 & 67 \\
\hline $\begin{array}{l}\text { Rehmannia glutinosa Libosch. (Prepared) (熟地黄), Ligusticum chuanxiong Hort. (川芦), } \\
\text { Angelica sinensis (Oliv.) Dlels (當歸) }\end{array}$ & 0.212 & 0.835 & 1.524 & 66 \\
\hline $\begin{array}{l}\text { Eclipta prostrata L. (旱蓮草), Polygonum multiflorum Thunb. (何首烏), Ligustrum lucidum Ait. } \\
\text { (女貞子) }\end{array}$ & 0.167 & 0.776 & 2.522 & 52 \\
\hline $\begin{array}{l}\text { Paeonia lactiflora Pall. (白苻藥), Rehmannia glutinosa Libosch. (Prepared) (熟地黄), Angelica } \\
\text { sinensis (Oliv.) Dlels (當歸) }\end{array}$ & 0.154 & 0.842 & 1.536 & 48 \\
\hline $\begin{array}{l}\text { Ligustrum lucidum Ait. (女貞子), Polygonum multiflorum Thunb. (何首鳥), Angelica sinensis } \\
\text { (Oliv.) Dlels (當歸) }\end{array}$ & 0.154 & 0.667 & 1.216 & 48 \\
\hline $\begin{array}{l}\text { Lycium barbarum L. (枸杞子), Polygonum multiflorum Thunb. (何首烏), Angelica sinensis (Oliv.) } \\
\text { Dlels (當歸) }\end{array}$ & 0.151 & 0.904 & 1.611 & 47 \\
\hline $\begin{array}{l}\text { Ligusticum chuanxiong Hort. (川芦), Polygonum multiflorum Thunb. (何首鳥), Rehmannia } \\
\text { glutinosa Libosch. (Prepared) (熟地黄) }\end{array}$ & 0.151 & 0.573 & 1.305 & 47 \\
\hline $\begin{array}{l}\text { Paeonia lactiflora Pall. (白䓁藥), Ligusticum chuanxiong Hort. (川芦), Angelica sinensis (Oliv.) } \\
\text { Dlels (當歸) }\end{array}$ & 0.147 & 0.885 & 1.614 & 46 \\
\hline $\begin{array}{l}\text { Angelica sinensis (Oliv.) Dlels (當歸), Cuscuta chinensis Lam. (菟絲子), Polygonum multiflorum } \\
\text { Thunb. (何首烏) }\end{array}$ & 0.144 & 0.804 & 1.433 & 45 \\
\hline
\end{tabular}




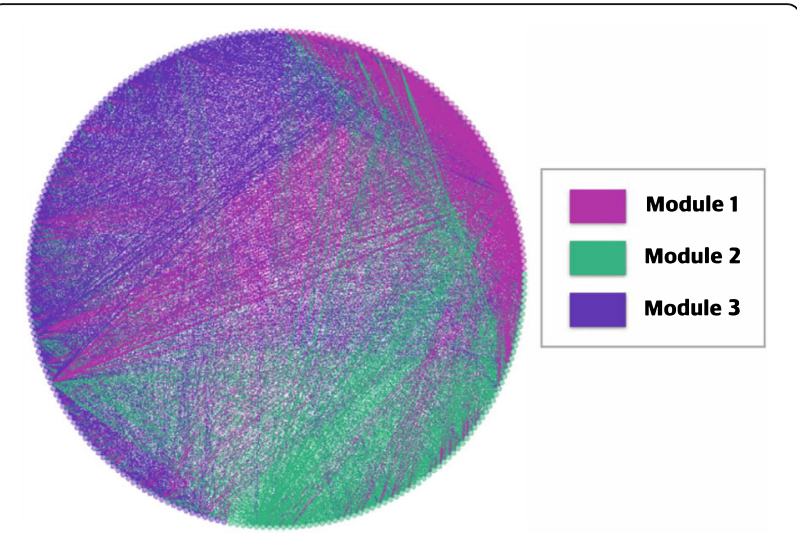

Fig. 2 Herb network of alopecia prescription based on modularity analysis

(Prepared). Ligusticum chuanxiong Hort., Polygonum multiflorum Thunb., and Angelica sinensis (Oliv.) Dlels was the most frequently used three-herb combination. Using the network analysis method, we classified the herbs into three modules. The meridian entry (歸經) of many herbs in module 1 was "Liver," whereas that in module 3 was "Stomach".

The meridian tropism theory is important in traditional East Asian medicine-both pharmacologically and in clinical practice. [74] According to meridian tropism theory, medicinal herbs have a certain $q i$ and flavor (氣味), and they exhibit curative effects on selected meridians. Therefore, depending on whether it belongs to the viscera or bowel group (藏腑), each medicinal herb is mainly used in a specific region. In other words, meridian tropism is a theory of the orientation of drug action. [75] Several experimental studies have presented evidence for meridian tropism theory. [74-76]

In the present study, the internal medicine group-Polygonum multiflorum Thunb., Angelica sinensis (Oliv.) Dlels, Rehmannia glutinosa Libosch. (Prepared), Ligusticum chuanxiong Hort., and Poria cocos (Schw.) Wolf-appeared in order. When we analyzed the top 10 medicinal herbs in the internal medicine group, every herb except for Ligusticum chuanxiong Hort. belonged to the viscera meridian (藏), not the bowel meridian (腑). [12] In the external application group-Platycladus orientalis (L.) Franco, Angelica dahurica (Fisch. ex Hoffm.) Benth. et Hook.f., Vitex trifolia L. var. simplicifolia Cham., Ligusticum chuanxiong Hort., and Aconitum carmichaelii Debx.-appeared in order. Six herbs in external application group belong to the bowel meridian. [12] These differences in meridian tropism between internal and external medicine may be associated with the drug absorption pathways or medicinal guide herb (引經藥). [77] The category of each medicinal herb also differed. In the internal medicine group, six herbs belonged to the tonifying and replenishing medicinal category. However, in the external application group, three herbs were exterior-releasing medicinals, and three were blood-activating and stasis-dispelling medicinals (Table 1).

We identified frequently used two-herb and three-herb set combinations (Tables $2 \& 3$ ). Polygonum multiflorum Thunb., Angelica sinensis (Oliv.) Dlels, Ligusticum chuanxiong Hort. and Rehmannia glutinosa Libosch. (Prepared) are the main herbs used in alopecia treatment. The six two-herb combinations of the four main herbs were the top six combinations of two-herb sets. These four main herbs were also important in the three-herb sets. However, the three-herb combination of Polygonum multiflorum Thunb., Ligusticum chuanxiong Hort., and Rehmannia glutinosa Libosch. (Prepared) occupied the relatively low 8th place. Paeonia lactiflora Pall. did not appear in the two-herb sets, but it was frequently observed in the three-herbs sets, indicating that this herb is used as an adjunct in alopecia treatment.

Interestingly, the lift value of the Ligustrum lucidum Ait. and Eclipta prostrata L. combination was higher than the frequency and support values, and these herbs often appeared together with Polygonum multiflorum Thunb. or Angelica sinensis (Oliv.) Dlels. That said, all the medicinal herbs appeared frequently. In contrast, in the case of Ligustrum lucidum Ait. and Eclipta prostrata L., the lift value was higher than the frequency of each medicinal herb, indicating that Ligustrum lucidum Ait. and Eclipta prostrata L. are usually prescribed together. The herbal formula name of the Ligustrum lucidum Ait. and Eclipta prostrata L. combination is Yijihwan (二至 丸). It has antioxidant activity and has been prescribed for hair loss in clinical practice. [78] Among the three-herb sets, the lift value of the Ligustrum lucidum Ait., Eclipta prostrata L., and Polygonum multiflorum Thunb. combination was also relatively high.

When we use the ARM method, the number of herbs that comprise each herb set should be determined in advance. For this reason we only identified frequently used two-herb and three-herb sets (Tables $2 \& 3$ ), and we used network analysis to assess the relationships of all medicinal herbs used to treat hair loss, regardless of the number of herbs in the set (Figs. 2 \& 3). We reviewed previous literature regarding pattern identification in alopecia. $[6,7,79-81]$ Blood heat engendering wind (血熱生 風), blood stasis due to $q i$ stagnation (氣滯血瘀), dual deficiency of $q i$ and blood (氣血兩虛), liver-kidney depletion (肝腎不足), and spleen-stomach dampness-heat (脾胃濕 熱) were the major pattern identifications in alopecia. Pathology was classified in terms of the viscera and bowels (臟腑) theory or the $q i$ and blood (氣血) theory.

According to our network analysis, Module 1 herbs affect the "Liver" meridian more and seem to tonify $q i$ and blood. [82] Module 3 herbs belong to the "Stomach" meridian more and seem to help digestion and absorption. Module 2 herbs seem to act on body surfaces, and 
Table 4 Meridian tropism and category of the top 20 herbs in each network module

\begin{tabular}{|c|c|c|c|c|c|c|c|c|c|c|c|c|c|c|c|}
\hline $\bar{M}$ & Medicinal Herb & W & Category & $\begin{array}{l}\mathrm{LR} \\
\text { (肝) }\end{array}$ & $\begin{array}{l}\mathrm{HT} \\
\text { (心) }\end{array}$ & $\begin{array}{l}P C \\
\text { (心包) }\end{array}$ & $\begin{array}{l}\mathrm{SP} \\
\text { (脾) }\end{array}$ & $\begin{array}{l}L U \\
\text { (肺) }\end{array}$ & $\begin{array}{l}\mathrm{Kl} \\
\text { (腎) }\end{array}$ & $\begin{array}{l}\mathrm{GB} \\
\text { (膽) }\end{array}$ & $\begin{array}{l}\mathrm{SI} \\
\text { (小腸) }\end{array}$ & $\begin{array}{l}\text { TE } \\
\text { (三焦) }\end{array}$ & $\begin{array}{l}\text { ST } \\
\text { (胃) }\end{array}$ & $\begin{array}{l}\mathrm{LI} \\
\text { (大腸) }\end{array}$ & $\begin{array}{l}\mathrm{BL} \\
\text { (膀胱) }\end{array}$ \\
\hline 1 & Polygonum multiflorum Thunb. (何首烏) & 1175 & 17 & $\mathrm{Y}$ & & & & & $\mathrm{Y}$ & & & & & & \\
\hline 1 & Angelica sinensis (Oliv.) Dlels (當歸) & 1100 & 17 & Y & Y & & Y & & & & & & & & \\
\hline 1 & $\begin{array}{l}\text { Rehmannia glutinosa Libosch. (Prepared) } \\
\text { (熟地黄) }\end{array}$ & 956 & 17 & Y & & & & & Y & & & & & & \\
\hline 1 & Ligusticum chuanxiong Hort. (川节) & 904 & 12 & Y & & Y & & & & Y & & & & & \\
\hline 1 & Ligustrum lucidum Ait. (女貞子) & 720 & 17 & Y & & & & & Y & & & & & & \\
\hline 1 & Eclipta prostrata L. (早蓮草) & 644 & 17 & Y & & & & & Y & & & & & & \\
\hline 1 & Lycium barbarum L. (枸杞子) & 622 & 17 & Y & & & & Y & Y & & & & & & \\
\hline 1 & Rehmannia glutinosa Libosch. (生地黄) & 603 & 2 & Y & Y & & & & Y & & & & & & \\
\hline 1 & Cuscuta chinensis Lam. (菟絲子) & 591 & 17 & Y & & & Y & & Y & & & & & & \\
\hline 1 & $\begin{array}{l}\text { Astragalus membranaceus (Fisch.) Bge. } \\
\text { (黃芪) }\end{array}$ & 564 & 17 & & & & Y & Y & & & & & & & \\
\hline 1 & Paeonia lactiflora Pall. (白苟藥) & 535 & 17 & Y & & & Y & & & & & & & & \\
\hline 1 & Salvia miltiorrhiza Bge. (丹蔘) & 484 & 12 & Y & Y & Y & & & & & & & & & \\
\hline 1 & Morus alba L. (桑椹) & 481 & 17 & Y & Y & & & & Y & & & & & & \\
\hline 1 & Sesamum indicum L. (黑芝麻) & 441 & 17 & Y & & & & & Y & & & & & Y & \\
\hline 1 & $\begin{array}{l}\text { Platycladus orientalis (L.) Franco } \\
\text { (側柏葉) }\end{array}$ & 355 & 11 & Y & & & & Y & & & & & & Y & \\
\hline 1 & Gastrodia elata BI. (天麻) & 288 & 15 & Y & & & & & & & & & & & \\
\hline 1 & Carthamus tinctorius L. (紅花) & 284 & 12 & Y & Y & & & & & & & & & & \\
\hline 1 & $\begin{array}{l}\text { Codonopsis pilosula (Franch.) Nannf. } \\
\text { (唐蔘) }\end{array}$ & 232 & 17 & & & & Y & Y & & & & & & & \\
\hline 1 & $\begin{array}{l}\text { Chaenomeles speciosa (Sweet) Nakai } \\
\text { (木瓜) }\end{array}$ & 230 & 4 & Y & & & Y & & & & & & & & \\
\hline 1 & Polygonatum sibiricum Red. (黃精) & 215 & 17 & & & & Y & Y & Y & & & & & & \\
\hline 1 & Total & - & $=$ & 17 & 5 & 2 & 7 & 5 & 10 & 1 & 0 & 0 & 0 & 2 & 0 \\
\hline 2 & $\begin{array}{l}\text { Saposhnikovia divaricata (Turcz.) } \\
\text { Schischk. (防風) }\end{array}$ & 85 & 1 & Y & & & Y & & & & & & & & Y \\
\hline 2 & Paeonia suffruticosa Andr. (牧丹皮) & 83 & 2 & Y & Y & & & & Y & & & & & & \\
\hline 2 & Panax ginseng C.A.Mey. (人蔘) & 82 & 8 & & & & Y & Y & Y & & & & & & \\
\hline 2 & $\begin{array}{l}\text { Platycladus orientalis (L.) Franco } \\
\text { (柏子仁) }\end{array}$ & 62 & 14 & & Y & & & & Y & & & & & Y & \\
\hline 2 & $\begin{array}{l}\text { Zanthoxylum schinifolium Sieb. et } \\
\text { Zucc. (蜀椒) }\end{array}$ & 61 & 7 & & & & Y & Y & Y & & & & Y & & \\
\hline 2 & Dendrobium nobile Lindl. (石斛) & 60 & 17 & & & & & & Y & & & & Y & & \\
\hline 2 & Cinnamomum cassia Presl (肉桂) & 60 & 7 & Y & Y & & Y & & Y & & & & & & \\
\hline 2 & $\begin{array}{l}\text { Angelica dahurica (Fisch. ex Hoffm.) } \\
\text { Benth. et Hook.f. (白芷) }\end{array}$ & 57 & 1 & & & & & Y & & & & & Y & Y & \\
\hline 2 & Achyranthes bidentata BI. (牛膝) & 56 & 12 & Y & & & & & Y & & & & & & \\
\hline 2 & Eucommia ulmoides Oliv. (杜沖) & 51 & 17 & Y & & & & & Y & & & & & & \\
\hline 2 & Sophora flavescens Ait. (苦蔘) & 48 & 2 & Y & Y & & & & & & & & Y & Y & Y \\
\hline 2 & Schisandra chinensis (Turcz.) Baill. (五味子) & 46 & 18 & & Y & & & Y & Y & & & & & & \\
\hline 2 & Ligusticum sinense Oliv. (葈本) & 44 & 1 & & & & & & & & & & & & Y \\
\hline 2 & $\begin{array}{l}\text { Asarum heterotropoides Fr.Schmidt var. } \\
\text { mandshuricum (Maxim.) Kitag. (細辛) }\end{array}$ & 42 & 1 & & & & & Y & Y & & & & & & \\
\hline 2 & Cistanche deserticola Y.C.Ma (肉蓯蓉) & 40 & 17 & & & & & & Y & & & & & Y & \\
\hline 2 & Zingiber officinale Rosc. (乾薑) & 39 & 7 & & Y & & Y & Y & & & & & Y & & \\
\hline
\end{tabular}


Table 4 Meridian tropism and category of the top 20 herbs in each network module (Continued)

\begin{tabular}{|c|c|c|c|c|c|c|c|c|c|c|c|c|c|c|c|}
\hline $\bar{M}$ & Medicinal Herb & W & Category & $\begin{array}{l}\mathrm{LR} \\
\text { (肝) }\end{array}$ & $\begin{array}{l}\text { HT } \\
\text { (心) }\end{array}$ & $\begin{array}{l}P C \\
\text { (心包) }\end{array}$ & $\begin{array}{l}\mathrm{SP} \\
\text { (脾) }\end{array}$ & $\begin{array}{l}L U \\
\text { (肺) }\end{array}$ & $\begin{array}{l}\mathrm{Kl} \\
\text { (腎) }\end{array}$ & $\begin{array}{l}\mathrm{GB} \\
\text { (膽) }\end{array}$ & $\begin{array}{l}\mathrm{SI} \\
\text { (小腸) }\end{array}$ & $\begin{array}{l}\text { TE } \\
\text { (三焦) }\end{array}$ & $\begin{array}{l}\text { ST } \\
\text { (胃) }\end{array}$ & $\begin{array}{l}\text { LI } \\
\text { (大腸) }\end{array}$ & $\begin{array}{l}\mathrm{BL} \\
(\text { 膀胱 })\end{array}$ \\
\hline 2 & Tribulus terrestris L. (苼藜) & 37 & 15 & & & & & & & & & & & & \\
\hline 2 & Schizonepeta tenuifolia Briq. (荊芥) & 37 & 1 & Y & & & & Y & & & & & & & \\
\hline 2 & $\begin{array}{l}\text { Lycopus lucidus Turcz. var. hirtus } \\
\text { Regel (澤蘭) }\end{array}$ & 37 & 12 & Y & & & Y & & & & & & & & Y \\
\hline 2 & $\begin{array}{l}\text { Selaginella tamariscina (Beauv.) } \\
\text { Spring (卷柏) }\end{array}$ & 36 & 12 & Y & & & & & & Y & & & & & \\
\hline 2 & Total & - & $=$ & 9 & 6 & 0 & 6 & 7 & 11 & 1 & 0 & 0 & 5 & 4 & 4 \\
\hline 3 & Poria cocos (Schw.) Wolf (获苓) & 469 & 6 & & Y & & Y & & Y & & & & & & \\
\hline 3 & Glycyrrhiza uralensis Fisch. (甘草) & 353 & 8 & & & & & & & & & & & & \\
\hline 3 & Atractylodes macrocephala Koidz. (白术) & 294 & 8 & & & & Y & & & & & & Y & & \\
\hline 3 & Alisma orientale (Sam.) Juzep. (澤瀉) & 205 & 6 & & & & & & Y & & & & & & Y \\
\hline 3 & Bupleurum chinense DC. (柴胡) & 165 & 1 & Y & & & Y & & & Y & & & & & \\
\hline 3 & Crataegus pinnatifida Bge. (山楂) & 163 & 9 & Y & & & Y & & & & & & Y & & \\
\hline 3 & Dioscorea opposita Thunb. (山藥) & 155 & 8 & & & & Y & Y & Y & & & & & & \\
\hline 3 & Cornus officinalis Sieb. et Zucc. (山荣莫) & 140 & 18 & Y & & & & & Y & & & & & & \\
\hline 3 & Citrus reticulata Blanco (陳皮) & 129 & 8 & & & & Y & Y & & & & & Y & & \\
\hline 3 & Scutellaria baicalensis Georgi (黄芩) & 129 & 2 & Y & & & & Y & & Y & Y & & Y & Y & \\
\hline 3 & $\begin{array}{l}\text { Coix lacryma-jobi L. var. ma-yuen } \\
\text { (Roman.) Stapf (薏茨仁) }\end{array}$ & 125 & 6 & & & & Y & Y & & & & & Y & & \\
\hline 3 & Polygonum multiflorum Thunb. (夜交藤) & 119 & 14 & Y & Y & & & & & & & & & & \\
\hline 3 & Dictamnus dasycarpus Turcz. (白鮮皮) & 114 & 2 & & & & Y & & & & & & Y & & Y \\
\hline 3 & Pinellia ternata (Thunb.) Breit. (半夏) & 99 & 13 & & & & Y & Y & & & & & Y & & \\
\hline 3 & Zingiber officinale Rosc. (生薑) & 98 & 1 & & & & Y & Y & & & & & Y & & \\
\hline 3 & Gardenia jasminoides Ellis (栃子) & 95 & 2 & Y & Y & & & Y & & & & Y & Y & & \\
\hline 3 & Artemisia capillaris Thunb. (茵蔯蒿) & 89 & 6 & Y & & & Y & & & Y & & & Y & & \\
\hline 3 & Ziziphus jujuba Mill. (大霜) & 89 & 8 & & & & Y & & & & & & Y & & \\
\hline 3 & Plantago asiatica L. (車前子) & 82 & 6 & Y & & & & Y & Y & & & & & & \\
\hline 3 & Atractylodes lancea (Thunb.) DC. (蒼术) & 80 & 5 & & & & Y & & & & & & Y & & \\
\hline 3 & Total & - & $=$ & 8 & 3 & 0 & 13 & 8 & 5 & 3 & 1 & 1 & 12 & 1 & 2 \\
\hline
\end{tabular}

Category of each medicinal herb: 1, Exterior-releasing medicinal (解表藥); 2, Heat-clearing medicinal (清熱藥); 4, Wind-dampness dispelling medicinal (祛風濕藥); 5, Dampness-resolving medicinal (化濕藥); 6, Dampness-draining diuretic medicinal (利水滲濕藥); 7, Interior-warming medicinal (溫裏藥); 8, Qi-regulating medicinal (理氣藥); 9, Digestant medicinal (消食藥); 11, Hemostatic medicinal (止血藥); 12, Blood-activating and stasis-dispelling medicinal (活血祛瘀藥); 13, Cough-suppressing and panting-calming medicinal (止咳平喘藥); 14, Tranquillizing medicinal (安神藥); 15, Liver-pacifying medicinal (平肝藥); 17, Tonifying and replenishing medicinal (補益藥); 18, Astringent medicinal (收澁藥)

$M$ Module, $W$ Weighted degree

Meridian tropism: BL Bladder meridian, GB Gall bladder meridian, $H T$ Heart meridian, KI Kidney meridian, LI Large intestine meridian, $L R$ Liver meridian, $L U$ Lung meridian, PC Pericardium meridian, SI Small intestine meridian, SP Spleen meridian, ST, Stomach meridian, TE Triple energizer meridian

they tend to be used externally, although further research is needed in this regard. These modules were similar to the traditional pattern identification framework derived from alopecia literature reviews. [6, 7, 79-81] In the present study, we reconfirmed the that Module 1 comprises tonifying "Liver" and "Kidney" strategies, and that Module 3 belongs more to the "Stomach" meridian, indicating that treatment of digestion and absorption are important in alopecia treatment.

Among the top 10 herbs in the internal medication group, none belonged to Module 2. All herbs except for Poria cocos (Schw.) Wolf and Glycyrrhiza uralensis Fisch. belonged to Module 1 and the "Liver" meridian (Table 1). All herbs except for Ligusticum chuanxiong Hort. belonged to the viscera (藏) group and not the bowel (腑) group. In contrast, of the top 10 herbs in the external application group, five belonged to module 2 . They also affected bowel meridians such as the "Stomach," "Large intestine," and "Urinary bladder." Thus, it may be that Module 2 is associated with external application, but further study will be needed, as we only conducted network analysis on the internal medicine group. Many of herbs in Module 3 belong more to the "Stomach" meridian. However, there were not module 3 medicinal herb in the 


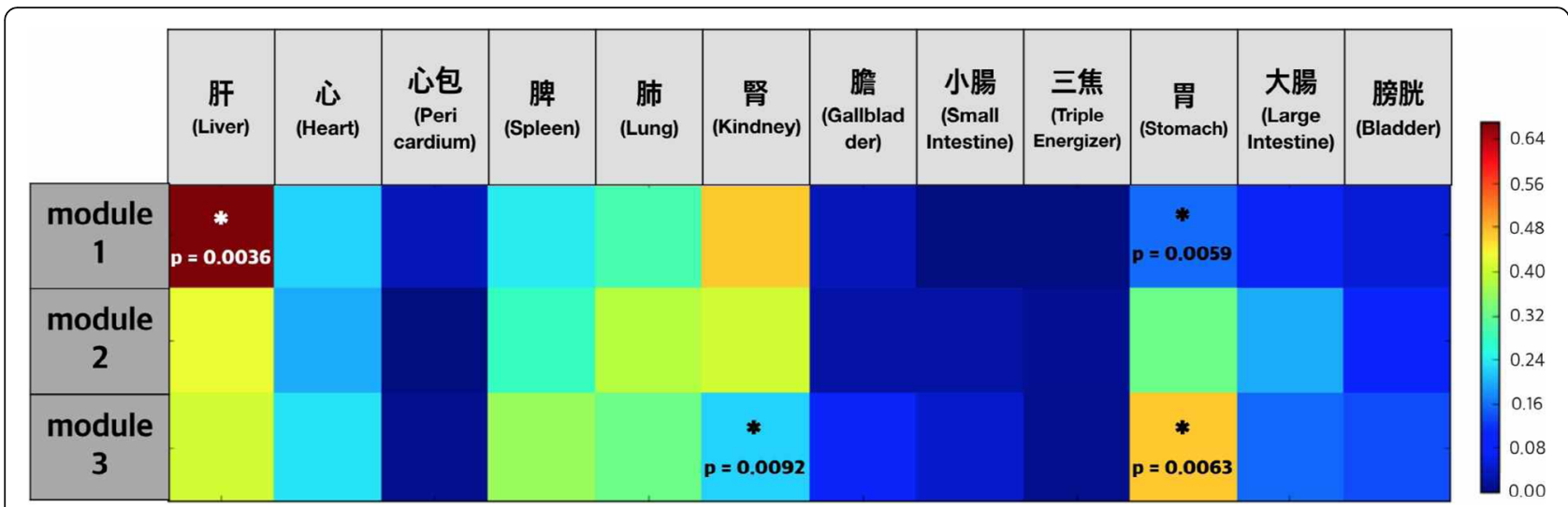

Fig. 3 Occurrence ratio of associated meridians of herbs within each module

internal and external groups top 10 herbs, with the exception of Poria cocos (Schw.) Wolf and Glycyrrhiza uralensis Fisch., indicating that treatment of digestion and absorption, which are related to Module 3, may be an adjunctive strategy in traditional Asian medicine. However, further research is needed in this regard.

Additional analysis was conducted on the top 20 medicinal herbs of each module (Table 4). In Module 1, 13 herbs were tonifying and replenishing medicinals (補益 藥), mostly oriented towards the "Liver" and "Kidney" meridians. Therefore, Module 1 herbs are characterized as tonifying the "Liver" and "Kidney" meridians. Five dampness-draining diuretic medicinals (利水滲濕藥) and five $Q i$-regulating medicinals (理氣藥) occupy half of Module 3. Most of these were oriented towards the "Spleen" and "Stomach" meridians. Therefore, Module 3 herbs are related to digestive function.

Module 2 comprised five exterior-releasing medicinals (解表藥), three interior-warming medicinals (溫裏藥), and three blood-activating and stasis-dispelling medicinals (活血祛瘀藥). [12, 13] Thus, Module 2 was apparently associated with excretion and divergence., Presumably, Module 2 herbs act on the body surface or are external medicines, although further research is needed in this regard.

Existing studies on pattern identification have taken a top-down theoretical approach. In contrast, the present research adopted a practical, bottom-up approach based on formulas that are prescribed in clinical practice. We conducted this novel approach to pattern identification by carrying out a network analysis of medicinal herbs used in alopecia treatment. We rediscovered the classical pattern identification of alopecia treatment, and we suggest that clinicians adopt a "Liver" or "Stomach"-oriented approach to alopecia treatment.

The current research had several strengths. To our knowledge, this was the first study that used bioinformatics methods and searched Chinese, English, and
Korean databases to assess which medicinal herbs have been used to treat alopecia. We adopted a practical network analysis approach based on formulas that are frequently used in clinical practice, rather than a theoretical/literature approach. Using this method, we explored the frequency, combination patterns, and meridian tropism of medicinal herbs used in alopecia treatment. We also classified herbs into three modules, confirming the value of classical pattern identification and the meridian tropism theory. Moreover, we explored the pathology of alopecia from the perspective of traditional east Asian medicine.

Our data mining methodology, which employed ARM and network analysis, also had several strengths. Firstly, in the ARM method, the number of herbs comprising the combination must be determined in advance. To overcome such shortcomings, we used network analysis to look at the overall combination pattern of medicinal herbs without limiting the number of herbs in the combination. Secondly, previous top-down research based on ancient literature has offered hypotheses about the pattern identification category of alopecia. In contrast, our bottom-up study categorized herbs into three modules based on the combination patterns of the formula. Lastly, previous research was limited in that it could only "qualitatively" interpret the characteristics of medicinal herbs or formulas used in alopecia treatment. We overcame this limitation by extracting significant "quantitative" characteristics using the permutation test.

Our research also had several limitations. The present study was based on the frequency of formulas used in clinical practice and literature. For this reason, we could not evaluate new candidate medicinal herbs emerging from recent clinical/experimental studies, neither could we reflect the importance of medicinal herb dose in each formula. Relatedly, we did not evaluate the clinical effectiveness of each formula in our study. Further clinical/experimental studies are needed to assess 
whether the classifications derived from our research have real meaning. Meridian tropism theory is controversial and may not accurately reflect the characteristics of each medicinal herb. Finally, we did not analyze external medicine, and the heterogeneity within Module 2 was not completely resolved.

The present research raises several indications for future research. We should analyze externally applied alopecia treatments, and we need to conduct a proof-of-concept study to corroborate our research. Using network pharmacologic analysis of medicinal herbs in each module, a hair loss mechanism could be identified based on meridian tropism theory (traditional medicine theory). Such studies may also indicate the pharmacological mechanism of hair loss treatment (western medicine theory). Multi-component, multi-target concepts are essential in herbal medicine pharmacology. Thus, we could propose new research methodology based on the techniques used in the present study. This methodology could be utilized to develop new hair loss drugs from natural products.

\section{Conclusions}

We identified the frequency and characteristics of medicinal herbs used in alopecia treatment. The most frequently used two-herb combination in alopecia treatment consisted of Polygonum multiflorum Thunb. and Angelica sinensis (Oliv.) Dlels. The most frequently used three-herb combination was Polygonum multiflorum Thunb., Angelica sinensis (Oliv.) Dlels, and Ligusticum chuanxiong Hort. Based on the meridian tropism theory, we used network analysis to identify three modules of herbs that can treat alopecia. We found a "Liver"-oriented module and a "Stomach"-oriented module, and confirmed the value of classical meridian tropism theory and pattern identification. However, further clinical/experimental study is needed to prove the significance of this concept and methodology.

\section{Additional file}

Additional file 1: Search strategy according to database. Individual search strategies for each database (DOCX $15 \mathrm{~kb}$ )

\begin{abstract}
Abbreviations
ARM: Association Rule Mining; CAM: Complementary and Alternative Medicine; CENTRAL: Central Register of Controlled Trials; CNKI: China National Knowledge Infrastructure Database; FDA: USA., the Food and Drug Administration of the United States; KIOM: Korea Institute of Oriental Medicine; OASIS: Oriental Medicine Advanced Searching Integrated System; TCM: Traditional Chinese Medicine
\end{abstract}

\section{Funding}

This work was supported by a National Research Foundation of Korea Grant, funded by the Korean Government (NRF-2017R1A1A1A05001218).
Availability of data and materials

The datasets used and/or analyzed during the current study are available from the corresponding author upon reasonable request.

\begin{abstract}
Authors' contributions
KK planned the overall study protocol. $J L$ and WJ drafted the manuscript. YK and BK searched the articles and extracted the data. WJ analyzed and visualized the data. KK reviewed and supervised the entire process of this research. $J$ and WJ participated in critical revision of the manuscript. KK had final responsibility for the decision to submit for publication. All the authors have read and approved the final manuscript, and all fulfil the ICMJE criteria for authorship.
\end{abstract}

Ethics approval and consent to participate

Not Applicable.

Consent for publication

Not Applicable.

\section{Competing interests}

The authors declare that they have no competing interests.

\section{Publisher's Note}

Springer Nature remains neutral with regard to jurisdictional claims in published maps and institutional affiliations.

\section{Author details}

${ }^{1}$ Dongshin Korean Medicine Hospital, 351, Omok-ro, Yangcheon-gu, Seoul 07999, Republic of Korea. ${ }^{2}$ Chung-Yeon Medical Institute, 64,

Sangmujungang-ro, Seo-gu, Gwangju 61949, Republic of Korea.

${ }^{3}$ Acupuncture and Meridian Science Research Center, College of Korean Medicine, Kyung Hee University, 26 Kyungheedae-ro, Dongdaemun-gu, Seoul 02447, Republic of Korea. ${ }^{4}$ Department of Science in Korean Medicine, Graduate School, Kyung Hee University, 26 Kyungheedae-ro,

Dongdaemun-gu, Seoul 02447, Republic of Korea. ${ }^{5}$ College of Korean Medicine, Kyung Hee University, 26 Kyungheedae-ro, Dongdaemun-gu, Seoul 02447, Republic of Korea. ${ }^{6}$ Department of Clinical Korean medicine, Graduate School, Kyung Hee University, 26 Kyungheedae-ro, Dongdaemun-gu, Seoul 02447, Republic of Korea. ${ }^{7}$ Department of Ophthalmology, Otolaryngology \& Dermatology, College of Korean Medicine, Kyung Hee University, 26 Kyungheedae-ro, Dongdaemun-gu, Seoul 02447, Republic of Korea. ${ }^{8}$ Department of Ophthalmology, Otolaryngology \& Dermatology, Kyung Hee University Korean Medicine Hospital, 23 Kyungheedae-ro, Dongdaemun-gu, Seoul 02447, Republic of Korea.

Received: 9 November 2017 Accepted: 25 June 2018

Published online: 04 July 2018

\section{References}

1. Mounsey AL, Reed SW. Diagnosing and treating hair loss. Am Fam Physician. 2009;80:356-62.

2. Phillips TG, Slomiany WP, Allison R. Hair Loss: Common causes and treatment. Am Fam Physician. 2017;96:371-8.

3. Trüeb RM, Dias MFRG. Alopecia Areata: a comprehensive review of pathogenesis and management. Clin Rev Allergy Immunol. 2017;

4. Seo H-S, Lee D-J, Chung J-H, Lee C-H, Kim HR, Kim JE, et al. Hominis placenta facilitates hair re-growth by upregulating cellular proliferation and expression of fibroblast growth factor-7. BMC Complement Altern Med. 2016;16:187.

5. van den Biggelaar FJHM, Smolders J, Jansen JFA. Complementary and alternative medicine in alopecia areata. Am J Clin Dermatol. 2010;11:11-20.

6. Du X. Study on medication and prescription compatibility law of alopecia disease (in Chinese). Nanjing University of Chin Med. 2016;

7. Fu-chun SI, Xian-pei MENG. [analysis of the TCM syndrome and prescription rules of alopecia and leukotrichia (in Chinese)]. China J. Tradit. Chin. Med. Pharm. 2016;31:3785-8.

8. Liu Z, Guo F, Wang Y, Li C, Zhang X, Li H, et al. BATMAN-TCM: a bioinformatics analysis tool for molecular mechANism of traditional Chinese medicine. Sci Rep. 2016;6:21146. 
9. Yea S-J, Kim C, Kim J-H, Jang H-C, Kim S-K, Han J-M, et al. The analysis of traditional Korean Medicine's information circumstance and the future plan of OASIS. J Korean Med. 2010;31:49-62.

10. Pharmacopoeia Committee of the People's Republic of China. Chinese Pharmacopoeia 2015 edition. China: Chinese Medical Science and Technology Press; 2015.

11. Korea Institute of Oriental Medicine. Defining Dictionary for Medicinal Herbs[Korean, 'Hanyak Giwon Sajeon'](2017). Published on the Internet; http://boncho.kiom.re.kr/codex/ (accessed 2017-10-31).

12. Nationwide College of Korean Medicine Common Textbooks of Phytology Compilation Committee. Phytology. 3th ed. Seoul: Young Lim Publishing Co.; 2011.

13. Gao XM. Chinese Pharmacy. 8th ed. Beijing: Chinese Medicine Press; 2007.

14. Chen $\mathrm{H}-\mathrm{Y}$, Lin $\mathrm{Y}-\mathrm{H}$, Su H, Chen $\mathrm{Y}-\mathrm{C}$, Yang S-H, Chen J-L. Investigation on Chinese herbal medicine for primary dysmenorrhea: implication from a nationwide prescription database in Taiwan. Complement Ther Med. 2014; 22:116-25.

15. Hagberg AA, Schult DA, Structure SPJEN. Dynamics, and function using NetworkX. Proc. 7th Python Sci. Conf. 2008:11-5.

16. Mathieu B, Sebastien H, Gephi MJ. An open source software for exploring and manipulating networks. Int. AAAI Conf. Web Soc. Media third Int. AAAI Conf. Weblogs Soc. Media. 2009:361-2.

17. Blondel VD, Guillaume J-L, Lambiotte R, Lefebvre E. Fast unfolding of communities in large networks. J Stat Mech Theory Exp. 2008;P10008(12pp):2008.

18. Liu P, Liu S, Chen G, Wang P. Understanding channel tropism in traditional Chinese medicine in the context of systems biology. Front Med. 2013;7:277-9.

19. Bureau JP, Ginouves P, Guilbaud J, Roux ME. Essential oils and low-intensity electromagnetic pulses in the treatment of androgen-dependent alopecia. Adv Ther. 2003;20:220-9.

20. Gómez Grau E, Lladós Sevilla M, Mira J, Vivancos F. Effectiveness of a dietary supplement with serenoa serrulata and tocotrienol-tocopherol against female androgenetic alopecia and telogen effluvium. Report of a pilot study. Rev Argent Dermatol [Internet]. 2015;96. Available from: http://www. embase.com/search/results?subaction=viewrecord\&from=export\&id= L604468257

21. Greenberg $\mathrm{JH}$, Katz M. Treatment of androgenetic alopecia with a $7.5 \%$ herbal preparation. J Dermatol Treat. 1996;7:159-62.

22. Kessels AGH, Cardynaals RLLM, Borger RLL, Go MJTH, Lambers JCCA Knotternerus JA, et al. The effectiveness of the hair-restorer 'Dabao' ${ }^{\prime}$ in males with alopecia androgenetica. A clinical experiment. J Clin Epidemiol. 1991;44:439-47.

23. Liang $L$, He $Y$. [clinical study on the treatment of alopecia with plumblossom needle plus medicinal herb spray(in Chinese)]. Shanghai J. Acupunct. Moxibustion. 2004;23:22-3.

24. Noudeh GD, Sharififar F, Khazaeli P, Mohajeri E, Jahanbakhsh J. Formulation of herbal conditioner shampoo by using extract of fenugreek seeds and evaluation of its physicochemical parameters. Afr J Pharm Pharmacol. 2011; 5:2420-7.

25. Ohkuma M. Treatment of alopecia by Chinese drug, Hange-koboku-to combined with liquid nitrogen application and PUVA - the second report. J Tradit Med. 1998;15:422.

26. Rawal Prof RC, Gandhi P, Singh Prof TB, Narasimha Murthy KHHVSS. Clinical evaluation of hairbac tablet and oil in the management of diffuse hair loss: an open clinical study. Int J Res Ayurveda Pharm. 2013;4:564-9.

27. Ryu HJ, Yoo MG, Son SW. The efficacy of $3 \%$ minoxidil vs. combined $3 \%$ minoxidil and Korean red ginseng in treating female pattern alopecia. Int J Dermatol. 2014;53:e340-2.

28. Sharquie KE, Al-Obaidi HK. Onion juice (Allium cepa L.), a new topical treatment for alopecia areata. J Dermatol. 2002;29:343-6.

29. Togni S, Maramaldi G, Meneghin M, Giacomelli L, Eggenhoffner R. Effective oral treatment for scalp disorders: results from a double blind, placebocontrolled study. Esperienze Dermatol. 2016;8:187-91.

30. Wollina U, Hercogova J, Fioranelli M, Gianfaldoni S, Chokoeva AA, Tchernev $G$, et al. Successful treatment of alopecia areata with Dr. Michaels $(R)$ (Alopinex) product family. J Biol Regul Homeost Agents. 2016;30:83-7.

31. Wang Z, Cai J, Xin H, Wang H. [application of Chinese herbal medicine combined with plum - blossom buckle in hair loss nursing (in Chinese)]. China med. Cosmet Dermatol. 2016;7:74-6.

32. Jin HD, He X, Li Y, Ye LB, Zhang P. [clinical analysis of traditional Chinese medicine decoction combined with minoxidil tincture in treatment of seborrheic alopecia (in Chinese)]. China med. Cosmet Dermatol. 2016;7:50-2.
33. Liu X, Zhu L. [clinical effect of integrated traditional Chinese and western medicine therapy in the treatment of severe alopecia Areata (in Chinese)] Health med. Res. Pract. 2016;13:30-3.

34. Bao J, Zhang Y, Wu J. Clinical efficacy observation of herbal paste in treatment of androgenetic alopecia (in Chinese). J liaoning Univ TCM. 2016;18:130-1.

35. Lu J, Liu F. [Clinical observation on 200 cases of androgenic hair loss treated by traditional Chinese medicine (in Chinese)]. World latest. Med Inf. 2016;16:175.

36. Li Z, Sui K, Zhao N. Clinical observation on treating 112 cases of androgenetic alopecia by Shengfa wan (in Chinese). Clin. J. Chin Med. 2016:8:110-1.

37. Ye F, Qi YT. [Clinical observation on treatment of alopecia Areata and seborrheic hair loss by Yangxue Shengfa mixture (in Chinese)]. Yunnan J. Tradit. Chin. Med. Mater. Medica. 2016;37:27-8.

38. Liu H. Clinical study of traditional Chinese medicine combined with plum blossom needle treatment of androgenetic alopecia (in Chinese). Guangzhou University of Chin Med. 2016;

39. Xue J, Yao R, Wang Q. Curative effect and its mechanisms of Chinese traditional medicine for treatment of alopecia areata (in Chinese). Pract. J. Clin Med. 2016;13:81-3.

40. Zhao $H$, Song $B$, Wang $P$, Liang L, Tu H, Yuan J, et al. observation on the control of mild alopecia areata in Chinese adults treated with Chinese herbal medicine and plum blossom needle (in Chinese). Chin J Dermatovenereology Integr Tradit West Med. 2016;15:374-5.

41. Hui D. Study and clinical observation on treatment of alopecia Areata by hair cleansing combined with plum blossom needling (in Chinese). J Clin Med Lit. 2016;4873(4876):3.

42. Wang $\mathrm{C}$, Zhang $\mathrm{H}$, Zhou S. The curative effect observation of treating alopecia areata with Chinese traditional and western medicine and comprehensive nursing care (in Chinese). J Pract Dermatol. 2016;9:276-8.

43. Kim J, Park S. A case of alopecia areata treated with Korean medical treatment. Herb Formula Sci. 2016;24:124-30.

44. Lee J, Kang Y, Jeong Y, Ahn T. A case of extensive alopecia Areata treated with traditional oriental hair care products. J. Korean Orient. Ophthalmol. Otorhinolaryngol. Dermatol. 2009;22:269-80.

45. Ha KS, Song IS, Lee JL, Na HS, Shin JN. A case report of a child in alopecia totalis. J. Korean Orient. Pediatr. 2004;18:191-200.

46. Cho A, Hong S. A case report of alopecia treated by Gagamsunbangpaedok-tang (Jiājiǎnxiānfángbàidú-tāng) - focused on multipatched alopecia Areata with lymphadenopathy. J. Korean Orient. Ophthalmol. Otorhinolaryngol. Dermatol. 2014;27:130-9.

47. Hwangbo M, Jeong M, Seo H. A case report of child with alopecia Areata. J Korean Orient Pediatr. 2012;26:47-52.

48. Ju B, Choi Y, Yu S, Lee S. A case report on child with different types of alopecia. J. Korean Orient. Pediatr. 2013;27:53-64.

49. Hong J, Kang S, Jang J, Kang Y. A clinical trial on efficacy of Gagamchengyoung-tang(Jiājiǎnqīngyíng-tāng) in the alopecia patients with febrile tendency. J. Korean Orient. Ophthalmol. Otorhinolaryngol. Dermatol. 2013;26:19-29.

50. Kim S-Y, Kim J-H, Chae B-Y. An experimental study on the effect of Sineungyangjin-Dan applied to the treatment of alopecia. J Orient Med Surg Ophthalmol Otolaryngol. 1991;4:43-58.

51. Kim M, Ahn B. A study of hair loss Preventsion and hair growth promotion by Korean traditional Fomular. Korea J Herbol. 2004;19:9-20.

52. Kim NK, Du IS, Mun YJ, Woo WH. Clinical study on the effect of Sangmogen on the alopecia. Korean J Orient Physiol Pathol. 2005;19:270-8.

53. Kim P, Kim H, Roh S, Hwang C. Effect of DanGuiBoHyulTangGami-bang on the Alopecial and hair growth stimulation. J. Korean Orient. Ophthalmol. Otorhinolaryngol. Dermatol. 2004;17:38-60.

54. Nam H-J, Kim Y-B. Effect of Insamyangyoung-tang on the skin barrier function of hairless mice. J. Korean Med. 2007;28:18-26.

55. Hong J, Song M, Choi I, Sohn N, Chung S. Effect of Yikgeebohyul-tang (Yiqibŭxuè-tāng) on Hair Regrowth and Cytokine Changes on Hair-Removed C57BL/6 Mice. J. Korean Med. 2010;31:138-52.

56. Choi H, Hwang S, Lee J, Do E, Kim M, Kim M. Effects of Hair Tonic and Food including Korean Medicinal Herbs on Hair Growth in an Alopecia Model of C57BL/6 Mice. Korea J Herbol. 2011;26:119-24.

57. Lee M, Jo H, Kim T, Kim N, Jeong H, Lee C. Experimental Studies on the Hair Growth Activity of Mixed Extracts of Mylabris Phalerata Pall. And Drynariae Rhizoma in Spontaneous Alopecia Model and Normal C57BL/6N Mice. Korean J. Orient. Physiol. Pathol. 2008;22:778-90. 
58. Cho A, Hong S, Yoon Y. Gagamyeonryunggobon-dan(Jiājiǎnyánlínggùběndān) induces hair regrowth effect from activating hair follicle. J. Korean Orient. Ophthalmol. Otorhinolaryngol. Dermatol. 2016;29:65-80.

59. Kim N, Moon S, Kim M, Lee Y, Yoo W. Haeae-tang including Artemisia argyi folium promotes hair growth in hair-removed C57BL/6 mice. Korea J. Herbol. 2015;30:19-24.

60. Lee $\mathrm{S}$, Chung $\mathrm{S}$, Song M, Shin $\mathrm{H}$. Hair growth promoting effect of Saengbaleum(Shēngfà-y̆nn) application on hair-removed C57BL/6 mouse. J Orient Rehabil Med. 2007;17:101-21.

61. Kwon GJ, Lee CH, Lee MW, Mun YJ, Choi DH, Lee HJ, et al. Morphological studies on hair growth effect of Samultang-gamibang in alopecia Areata mice. Korean. J Orient Physiol Pathol. 2005;19:696-704.

62. Chinag H-C, Lee S-H, Kim N-K, Lim H-J, Hwang C-Y. Studies on the effect of medicinal plant extracts for the hair growth stimulation using in vivo and in vitro test models. J. Korean Orient. Ophthalmol. Otorhinolaryngol. Dermatol. 2002;15:53-79.

63. Choi W, Choi JH, Kim JH. Studies on the effects of medicinal plant extracts on the hair growth stimulation. J Korean Orient Ophthalmol Otorhinolaryngol Dermatol. 2002;15:80-103.

64. Han A, Sohn N, Chung S, Kim S, Song M. Study on effect of Saengbal-eumII(Shēngfà-yĭn-II) on hair regrowth promotion in C57BL/6 mice. J. Orient. Rehabil. Med. 2009;19:95-113.

65. Yun JH, Kim NK, Lim KS, Roh SS, Hwang CY. Study on the effect of Gamissanghwa-tang and each medicinal plant extract for the hair growth of the mice using in vivo and in vitro test. Korean J. Orient. Physiol. Pathol. 2004;18:561-70.

66. Jeon W-J, Jeong S-H, Han S-H, Jeong S-H, Shin G-J, Lee W-C. The clinical observation on 1 case of alopecia Areata with headache. J Korea Inst Orient Med Inform. 2001;7:1-7.

67. Do E, Hwang M, Kim S, Lee J, Yang D, Yang C, et al. The effect of Gyungokgo-gamibang extract on hair growth and protein expression in mice. Korea. J Herbol. 2011;26:9-14

68. Park W, Sung D, Kim D, Cho W, Lee H, Lee C, et al. The Effect of Hair Essence (HHRHG0202-80) Containing Five Herbal Extracts on Hair Growth ang the Prevention of Alopecia in vitro \& vivo. J. Korean Med. 2004;25:152-60.

69. Hwang KS, Lee MC. The effects of Saryuk-tang decoction on the growth of the hair in dogs and the endocrine in albino rats. J KyungHee Orient Med Coll. 1981;4:103-11.

70. Lee J, Lee J, Park H, Jung H, Ha I, Cho W, et al. The effects of traditional oriental hair care products on alopecia. J. Korean Orient. Ophthalmol. Otorhinolaryngol. Dermatol. 2009;22:145-52.

71. Lee $\mathrm{K}$, Hong $\mathrm{C}$, Lee $\mathrm{S}$, Sun $\mathrm{S}$, Lee $\mathrm{C}$. The efficacy and safety human study of Narasoo healing shampoo and hair tonic for Scalp's Lipids \& Moisture and hair growth -one center, one group pre-post comparison pilot human study. J. Korean Orient. Ophthalmol. Otorhinolaryngol. Dermatol. 2014;27:56-71.

72. Oh Y, Oh M, Roh S. The experimental study on the effect of herbal Exrtacts on hair growth and acnes. J. Korean Orient. Ophthalmol. Otorhinolaryngol. Dermatol. 2006;19:34-54

73. Lee $Y$, Kim J. The study of the oriental medicine extract on the hair growth Effect : I. The effect of the mixture extract of Polygoni multiflori Radix, Angelicae gigantis Radix and Lycii Fructus on the hair growth. Korea J. Herbol. 2004;19:83-90.

74. Zhao $Y$, Li Y, Wang $X$, Sun W. The experimental study of cortex Eucommiae on meridian tropsim: the distribution study of aucubin in rat tissues. J Pharm Biomed Anal. 2008;46:368-73.

75. Kang SY, Park Y-K. Comparison of the efficacy of the herbs for upper medication on glucose tolerance induced by high fat/high sucrose feeding-induced mice. Korea J. Herbol. 2014;29:1-8.

76. Xu FQ, Feng YY, Guo L, Guo GL, Yan BL. The effective method for investigation meridian tropism theory in rats. Afr J Tradit Complement Altern Med AJTCAM. 2013;10:356-67.

77. Kim D-I, Kim S-H, Choi M-S, Park S-D. A study on application of Korean medical prescriptions theory in developing transdermal medicine and Korean medical cosmetic preparation using oral herbal medicine. J Orient Obstet \& Gynecol. 2015;28:74-86.

78. Kang S-H, Kim E-Y, Rhyu M-R, Kim D-IA. Study on effects of Ligustri Lucidi Fructus, Ecliptae Herba and Yijihwan on antioxidant activity and blood pressure. J. Orient. Obstet. \& Gynecol. 2007;20:83-96.

79. Jang I, Ko W, Yoon $\mathrm{H}$. The latest trends of treatment for alopecia. J. Korean Orient. Ophthalmol. Otorhinolaryngol. Dermatol. 2015;28:12-28.
80. Jang I, Ko W, Yoon $\mathrm{H}$. The study about the comparison of Korean-western medicine on hair. J. Korean Orient. Ophthalmol. Otorhinolaryngol. Dermatol. 2016;29:1-13.

81. Baek S-Y, Im C-K, Kim K-J. Analysis of the research situations on alopecia published in the journal of oriental medicine. J East -West Med. 2012:37:31-9.

82. Pan $\mathrm{H}$, Chen $\mathrm{Z}$, Zhang $\mathrm{C}$. [research on medication rules of alopecia treatment based on data mining(in Chinese)]. Chin. Med. J Res Prac. 2016:30:65-8

\section{Ready to submit your research? Choose BMC and benefit from:}

- fast, convenient online submission

- thorough peer review by experienced researchers in your field

- rapid publication on acceptance

- support for research data, including large and complex data types

- gold Open Access which fosters wider collaboration and increased citations

- maximum visibility for your research: over $100 \mathrm{M}$ website views per year

At BMC, research is always in progress.

Learn more biomedcentral.com/submissions 